\title{
RNA-Based Optimum Design method for SPM type Magnetic Gears
}

\author{
Michinari Fukuoka, Kenji Nakamura, and Osamu Ichinokura \\ Graduate School of Engineering, Tohoku University, 6-6-05 Aoba Aramaki, Aoba-ku, Sendai 980-8579, Japan
}

\begin{abstract}
Magnetic gears, which can change torque and speed without any mechanical contacts, have some advantages in comparison with conventional mechanical gears as follows: low vibration and acoustic noise, high reliability, and low maintenance. This paper presents an optimum design method for a surface permanent magnet (SPM) magnetic gear based on reluctance network analysis (RNA). The RNA has desirable features including a simple analytical model, high-speed and accurate calculation, and ease of coupled analysis. The validity of the proposed method is proved by comparing with another method based on finite element analysis (FEA) and experiment.
\end{abstract}

Key words: Magnetic gear, optimum design, reluctance network analysis (RNA), finite element analysis (FEA)

\section{Introduction}

Magnetic gears can change torque and speed without mechanical contacts. Therefore, the magnetic gears have some attractive features in comparison with conventional mechanical gears such as low acoustic noise and vibration, high reliability, and low maintenance. Various kinds of magnetic gears have been introduced in previous patents and papers 1)-3). Among them, a planetary type magnetic gear ${ }^{1)}$ have attracted great interest ${ }^{4)}$, 5).

The planetary type magnetic gear consists of inner and outer rotors with surface-mounted permanent magnet (SPM), and ferromagnetic stationary pole pieces which are placed between the inner and outer rotors. It transmits mechanical power by modulating the magnet flux due to the pole pieces. Torque density of the planetary type magnetic gear is higher than the other magnetic gears because all the magnets on the inner and outer rotors contribute to transmit torque ${ }^{6}$.

In order to put the planetary type magnetic gear into practical application, establishment of an optimum design method for the magnetic gear is necessary. Nowadays, several number of general-purpose optimum design programs coupled with finite element analysis (FEA) have been placed on the market. However, FEA-based optimum design is not always advantageous because its analytical model is complicated and calculation time tends to be long.

Reluctance network analysis (RNA) is one of the practical solutions since an analytical model is simple, calculation accuracy and speed are relatively high, and dynamic analysis considering a rotational motion is easy to be performed ${ }^{7)}-9$ ).

In this paper, first the RNA model of an SPM type magnetic gear is described. The calculated torque is compared to FEA and experiment. Next, the RNA-based optimum design for an SPM type magnetic gear is presented. It is demonstrated that the proposed optimum method has high calculation accuracy with high speed.

\section{Characteristics calculation of SPM type magnetic gear}

\subsection{RNA model of SPM type magnetic gear}

Fig. 1 shows the structure and specifications of the SPM type magnetic gear used in the consideration. The inner and outer rotors have permanent magnets on their surfaces. The numbers of pole-pairs of the inner and outer rotors are 3 and 31, respectively. Hence, the gear ratio is 10.333 , which is given by a ratio of the inner and outer pole-pairs ${ }^{4}$. The pole pieces are placed between the inner and outer rotors. The number of pole pieces is 34 , which is given by the sum of the numbers of the inner and outer pole-pairs. Core material of the pole pieces and rotor back yokes is non-oriented silicon steel, and magnet material is sintered $\mathrm{Nd}-\mathrm{Fe}-\mathrm{B}$, of which residual flux density $B_{\mathrm{r}}$ is $1.25 \mathrm{~T}$ and coercive force $H_{\mathrm{c}}$ is $975 \mathrm{kA} / \mathrm{m}$, respectively.

In order to derive the RNA model, first of all, the magnetic gear is divided into multiple elements as shown in Fig. 2. The number of divisions in a circumferential direction is determined based on the number of the pole pieces so that the pole pieces are divided equally into an integral number. On the other hand, it is not necessary to divide the rotor magnets equally into an integral number because the magnetomotive forces (MMFs) of the rotor magnets are given by a continuous function of a rotor position in the RNA model as described later.

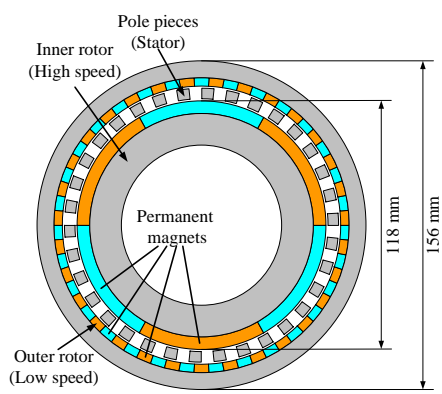

\begin{tabular}{ll}
\hline Stack length : & $10 \mathrm{~mm}$ \\
Airgap length : & $1 \mathrm{~mm}$ \\
Inner pole-pairs : & 3 \\
Outer pole-pairs : & 31 \\
Pole pieces number : & 34 \\
Gear ratio : & $1: 10.333$ \\
Permanent magnet & $(\mathrm{Nd}-\mathrm{Fe}-\mathrm{B})$ \\
Remanence : & $1.25 \mathrm{~T}$ \\
Coercivity : & $975 \mathrm{kA} / \mathrm{m}$
\end{tabular}

Fig. 1 Structure and specifications of the SPM type magnetic gear used in the consideration. 


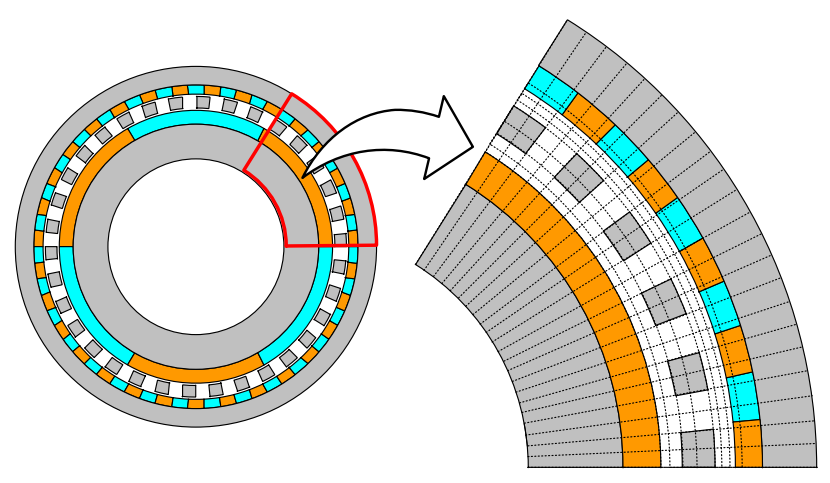

Fig. 2 Divisions of the magnetic gear based on RNA.

Each divided element is expressed in a two-dimensional unit magnetic circuit as shown in Fig. 3. The reluctances $R_{\mathrm{r}}$ and $R_{\theta}$ in the circuit are given by only dimensions of the divided element and magnetic property of the core material ${ }^{7}$.

The MMF of permanent magnet $f_{\mathrm{c}}$ is defined by

$$
f_{c}=H_{c} l_{m},
$$

where the length of the magnet is $l_{\mathrm{m}}$. Thus, the MMFs distribution of the inner and outer rotors $F_{h}(\theta)$ and $F_{l}(\theta)$ are given by the following continuous function so that the rotary motion can be expressed in the RNA model:

$$
\begin{aligned}
F_{k} & =H_{c}(\theta) l_{m k} \\
& =H_{c} l_{m k} \times \frac{2}{\pi} \tan ^{-1}\left(b \sin p_{k} \theta\right) \quad(k=h, l),
\end{aligned}
$$

where the coefficient $b$ is 5 , the number of the inner and outer pole-pairs are $p_{h}$ and $p_{l}$, and the length of the inner and outer rotor magnets are $l_{m h}$ and $l_{m l}$, respectively.

Fig. 4 shows a part of the RNA model obtained in the way described above. Fig. 4(a) illustrates the magnetic circuit on the $r-\theta$ plane. The number of division in a circumferential direction is 272 , that is, each pole piece is divided equally into 4 elements. Fig. 4(b) indicates the magnetic circuit on the $r-z$ plane. It is necessary to consider leakage flux in axial (z-axis) direction since the magnetic gear used in the consideration has a flat structure.

The number of divisions in a radial direction is 6 . Therefore the magnetic gear is divided into 2,176 elements.

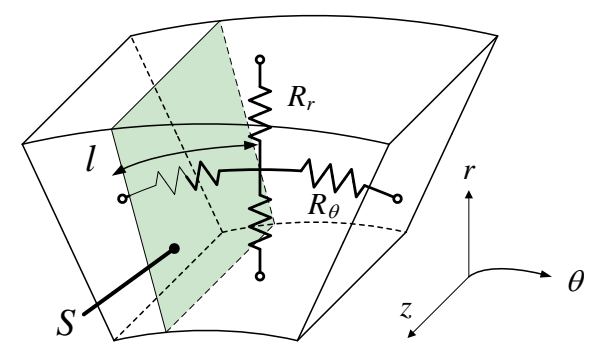

Fig. 3 Unit magnetic circuit.

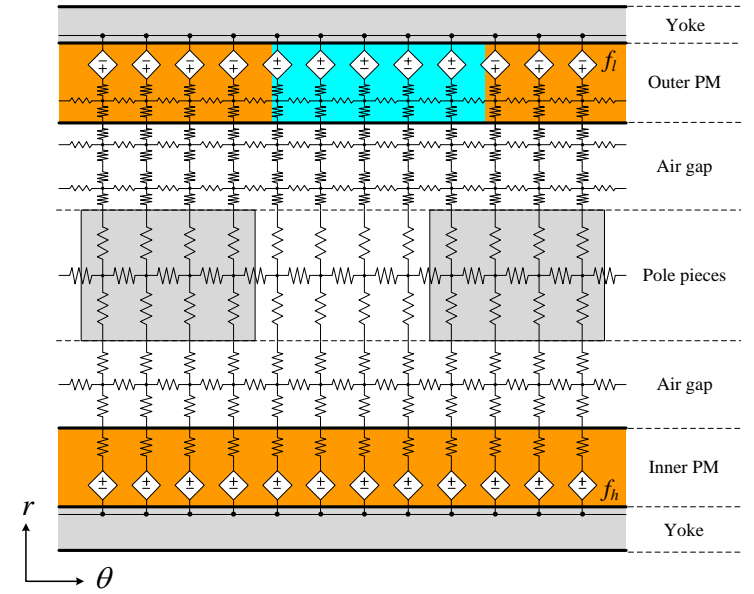

(a) Magnetic circuit on the $r-\theta$ plane.

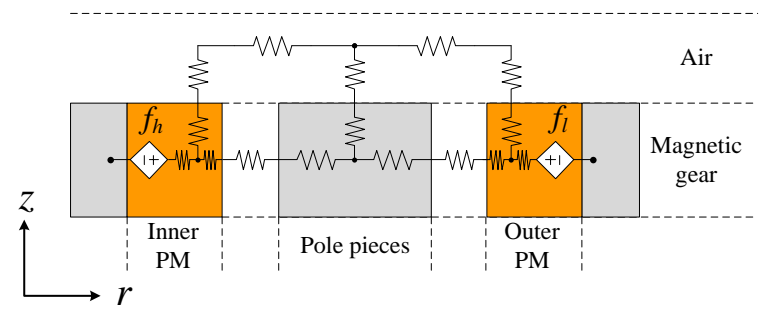

(b) Magnetic circuit on the $r-z$ plane.

Fig. 4 Expanded view of the RNA model.

\subsection{Steady state analysis}

Fig. 5 illustrates a flow diagram of steady state analysis using the RNA model. If the angular velocities of the inner and outer rotors $\omega_{h}, \omega_{l}$ are given first, both rotor positions $\theta_{h}, \theta_{l}$ are obtained from time integration of $\omega_{h}, \omega_{l}$. Next, the flux distribution in the RNA model of the magnetic gear is calculated, and then the generated torque of the both rotors is calculated by the following equation based on magnetic energy ${ }^{8)}$ :

$$
\tau=\frac{n_{\theta}}{2 \pi} \sum_{j=1}^{n_{\theta}} \phi_{k j} \times \Delta f_{k j} \quad(k=h, l),
$$

where the number of rotor divisions in a circumferential direction is $n_{\theta}$. The fluxes and the difference of MMFs in the permanent magnets are $\phi_{k j}$ and $\Delta f_{k j}$, respectively. All the above calculation can be performed simultaneously on SPICE which is a general purpose circuit simulator.

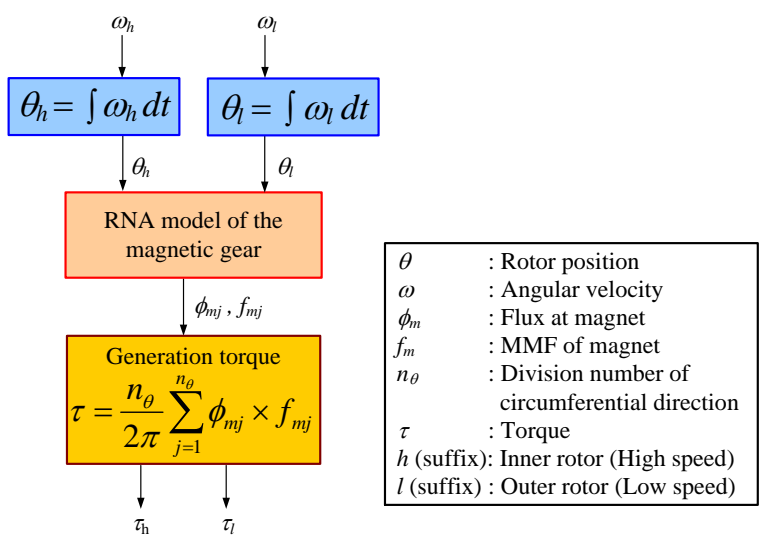

Fig. 5 Flow diagram of steady state analysis. 


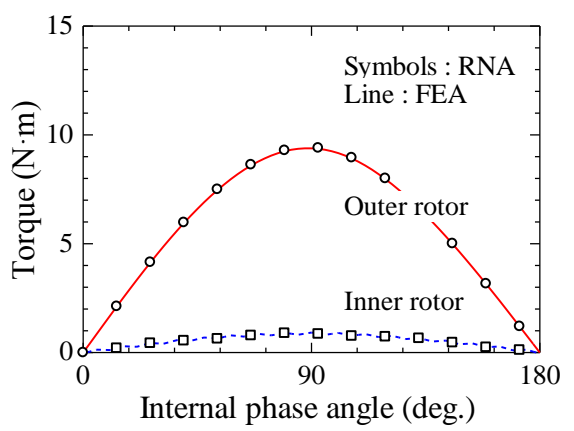

Fig. 6 Transmission torque characteristic.

Fig. 6 shows the transmission torque characteristic calculated by RNA and FEA, respectively. The internal phase angle is defined as the difference between $d$-axes of the inner and outer rotors. It is understood that the maximum transmission torque is obtained when an internal phase angle is $90 \mathrm{deg}$. in the same manner as conventional synchronous machines. The figure reveals that both calculated values are in good agreement. The calculation time of RNA is few minutes, while FEA is about 34 hours.

\subsection{Comparison with the experimental results}

On the basis of the above results, a trial SPM type magnetic gear, which has the same structure and specifications shown in Fig. 1, was manufactured.

Fig. 7 shows the general view of the experimental setup. The trial magnetic gear operates as a reduction gear on this system. The rotational speed of inner rotor is regulated at an arbitrary speed by the servomotor. The load torque is controlled by the hysteresis brake.

Fig. 8 shows the input and output speed characteristic obtained from no-load test. It is understood from the figure that the desired gear ratio of 10.33 can be obtained and the measured and calculated values are in good agreement.

Fig. 9(a) shows the transmission torque characteristics calculated by RNA and FEA. The calculated maximum torque of the magnetic gear is 9.51 $\mathrm{N} \cdot \mathrm{m}$. Fig. 9(b) shows the observed torque behavior when the load is gradually increasing. It is clear that the magnetic gear is stepped-out when the load is over the maximum torque in the same manner as conventional synchronous machines. The measured maximum torque of $9.47 \mathrm{~N} \cdot \mathrm{m}$ is almost agree well with the calculated one.

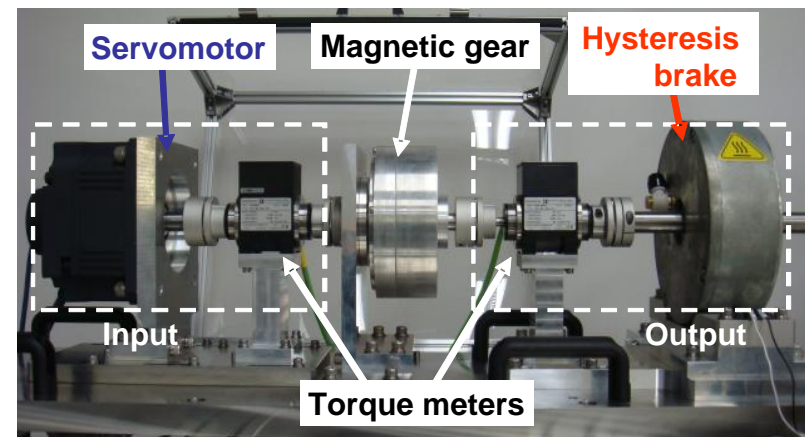

Fig. 7 General view of the experimental setup.

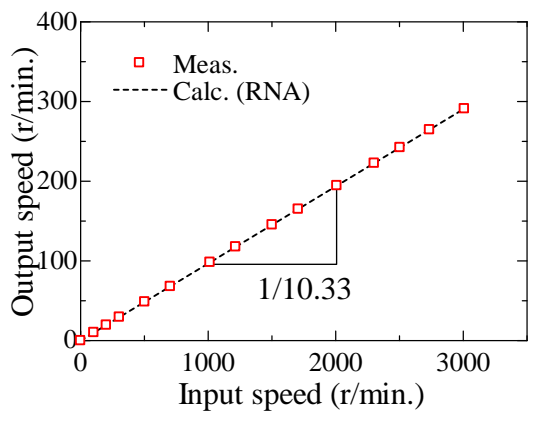

Fig. 8 Input and output speed characteristic.

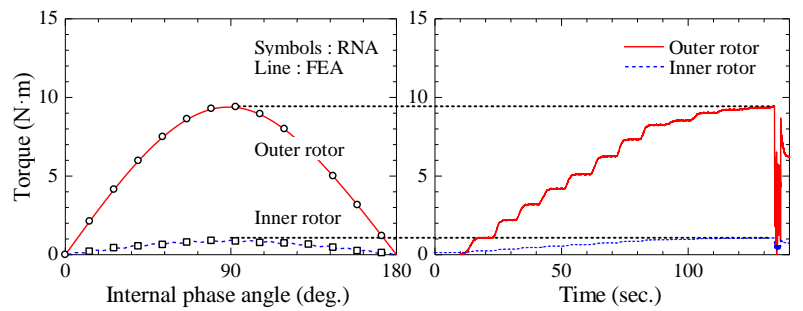

(a) Calculated torque.

(b) Observed torque.

Fig. 9 Comparison of calculated and measured torques.

\section{RNA-based optimum design method}

\subsection{Optimum design method for magnetic gear}

Since the magnetic gear has many design parameters such as lengths of the magnets, air gaps of the inner and outer rotors, etc., it is necessary for the establishment of an optimum design method with high calculation accuracy and high speed. Therefore, the RNA-based optimum design of the magnetic gear is presented.

Fig. 10 shows optimized parameters and fixed parameters of the magnetic gear. The radial lengths of inner and outer magnets, $l_{m h}, l_{m l}$, and the radial length of the pole piece $l_{p}$ are optimized to maximize the torque. On the other hand, the diameter and the stack length of the gear are fixed $156 \mathrm{~mm}$ and $10 \mathrm{~mm}$, respectively. The two air gap lengths are also fixed $1 \mathrm{~mm}$ each. Based on the above conditions, the optimized parameters $l_{m h}, l_{m l}$, and $l_{p}$ are changed from $1 \mathrm{~mm}$ to $15 \mathrm{~mm}$ with $1 \mathrm{~mm}$ step, respectively. Hence, the total combinations of the parameters are up to $15^{3}=3,375$.

In order to search the optimum combination efficiently, the RNA and a SIMPLEX method 10), which is one of the optimization algorithms, are combined.

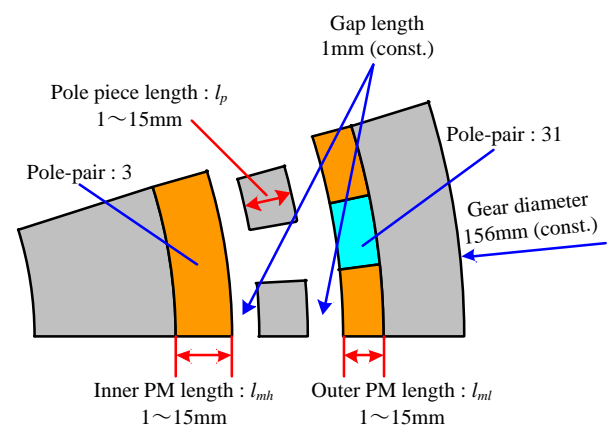

Fig. 10 Optimized parameters and fixed parameters. 


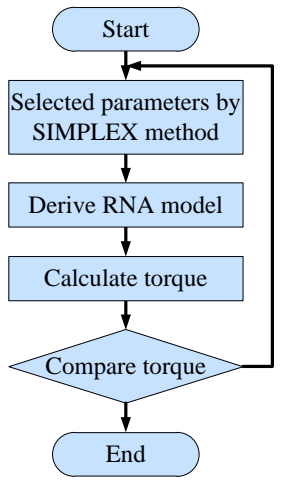

Fig. 11 Work flow diagram based on SIMPLEX.

Here, the magnetic gear is optimized using twodimensional RNA model in this paper, that is, influence of the leakage flux in axial direction is neglected.

Fig. 11 indicates a flow diagram of the RNA-based optimum design. When the parameters are given first, the RNA model of the magnetic gear of a certain design is derived, and then the torque is calculated. Next, the calculated torque of the certain design is compared to that of the other designs. Finally, if the toque is maximized, the optimization procedure is finished. If not, other combination of the parameters is selected based on the SIMPLEX method.

Fig. 12 shows the progress of the torque. It is understood that the optimum values can be found for the 45 th time by the proposed method. The maximum transmission torque is $25.9 \mathrm{~N} \cdot \mathrm{m}$, and $l_{\mathrm{mh}}, l_{\mathrm{ml}}$, and $l_{\mathrm{p}}$ are $15 \mathrm{~mm}, 7 \mathrm{~mm}$, and $4 \mathrm{~mm}$, respectively.

\subsection{Comparison with the FEA-based optimum design}

To validate the usefulness of the proposed optimum method, it is compared to the results obtained from the FEA-based optimum design. The optimum combination of $l_{\mathrm{mh}}, l_{\mathrm{ml}}$, and $l_{\mathrm{p}}$ is searched to maximize the transmission torque by two-dimensional FEA and the SIMPLEX method under the same condition.

Table 1 shows the comparison of the results obtained from RNA and FEA. The total calculation time of the proposed method is about 7 minutes, while it takes about 6 hours when the FEA is employed. The both optimum torques are in good agreement, however there is discrepancy between the optimum values of $l_{\mathrm{ml}}$ obtained from RNA and FEA.

In order to clarify the discrepancy, Fig. 13 shows the torque characteristics when $l_{\mathrm{ml}}$ is changed around the optimum value. It is understood from the figure that the

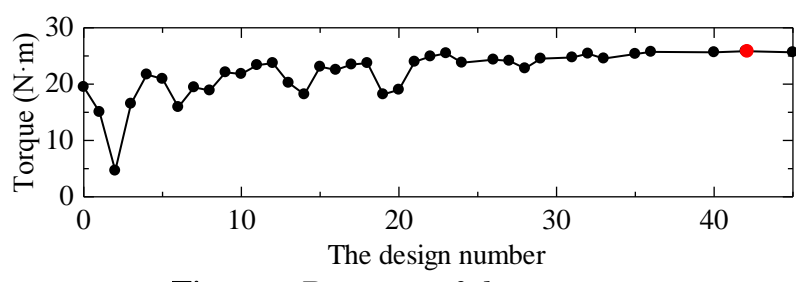

Fig. 12 Progress of the torque.
Table 1 Comparison of the results obtained from RNA and FEM.

\begin{tabular}{|c|l|r|r|}
\hline \multicolumn{2}{|c|}{} & \multicolumn{1}{|c|}{ RNA } & \multicolumn{1}{c|}{ FEM } \\
\hline \multirow{4}{*}{$\begin{array}{c}\text { Optimum } \\
\text { values }\end{array}$} & Torque & $25.9 \mathrm{~N} \cdot \mathrm{m}$ & $26.3 \mathrm{~N} \cdot \mathrm{m}$ \\
\cline { 2 - 4 } & $l_{m h}$ & $15 \mathrm{~mm}$ & $15 \mathrm{~mm}$ \\
\cline { 2 - 4 } & $l_{m l}$ & $7 \mathrm{~mm}$ & $4 \mathrm{~mm}$ \\
\cline { 2 - 4 } & $l_{p}$ & $4 \mathrm{~mm}$ & $5 \mathrm{~mm}$ \\
\hline \multicolumn{2}{|c|}{ Total calculation time } & $7 \mathrm{~min}$. & 6 hours \\
\hline
\end{tabular}

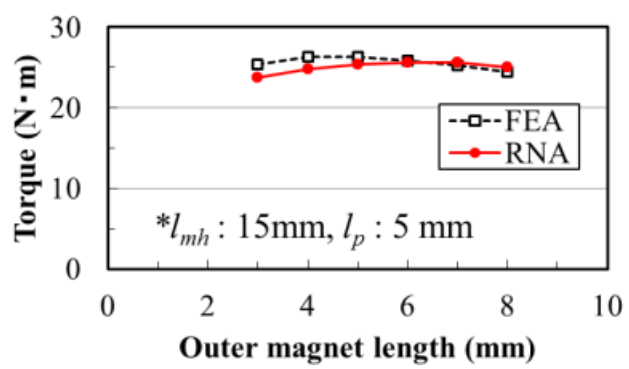

Fig. 13 Torque characteristics around the optimum value.

differences of the torque when $l_{\mathrm{ml}}$ changes from $4 \mathrm{~mm}$ to $7 \mathrm{~mm}$ in RNA and FEA are less than $4 \%$. Therefore, the difference between the optimum values of $l_{\mathrm{ml}}$ obtained from RNA and FEA is the allowable margin of error.

\section{Conclusion}

This paper presented an optimum design method for the SPM type magnetic gears based on RNA.

It was clear that the calculated values obtained from RNA are in good agreement with ones obtained from FEA and experiment, and that the RNA-based optimum design method can search the optimum combination of design parameters efficiently and accurately.

This work was supported by JSPS Grant-in-Aid for Scientific Research (B) (24360102), and Grant-in-Aid for JSPS Fellows $(24 \cdot 4456)$.

\section{References}

1)T. B. Martin, Jr., U.S. Patent 3378710 (1968).

2) D. E. Hesmondhalgh and D. Tipping, IEE Proc. B, Elect. Power Appl., 127, 129 (1980).

3) K. Tsurumoto and S. Kikushi, IEEE Trans. Magn., 23, 3622 (1987).

4) P. O. Rasmussen, T.O. Andersen, F.T. Jørgensen, and O. Nielsen, IEEE Trans. Ind. Applicat., 41, 764 (2005).

5) T. Ikeda, K. Nakamura, and O. Ichinokura, J. Mag. Soc. Jpn., 33, 130 (2009) (in Japanese)

6) K. Atallah and D. Howe, IEEE Trans. Magn., 37, 2844 (2001).

7) K. Tajima, Y. Anazawa, T. Komukai, and O. Ichinokura, EPE '97, 2, 6 (1997).

8) K. Nakamura, M. Ishihara, and O. Ichinokura, Proc. 17th Int. Conf. on Electrical Machines (ICEM 2006), PSA1-16 (2006).

9) M. Fukuoka, K. Nakamura, and O. Ichinokura, IEEE Trans. Magn., 47, 2414 (2011).

10) J. A. Nelder and R. Mead, Computer Journal, 7, 308 (1965).

Received October 19, 2012; Revised November 20, 2012;

Accepted December 13, 2012 